\title{
INDICADORES DE DESEMPENHO ECONÔMICO-FINANCEIRO DA PRODUÇÃO LEITEIRA EM PROPRIEDADES RURAIS DE FORMOSA DO SUL - SC
}

\author{
Indicators of Economic and Financial Performance of Dairy Production in \\ Rural Properties of Formosa do Sul - SC
}

\begin{abstract}
RESUMO
O estudo teve por objetivo comparar indicadores de desempenho econômico-financeiro da produção leiteira em propriedades rurais de Formosa do Sul-SC. Metodologicamente a pesquisa caracteriza-se como descritiva realizada por meio de levantamento, com análise de cunho quantitativo. A partir da identificação do patrimônio, dos custos e das receitas da atividade leiteira, identificaramse os principais indicadores de desempenho das 30 propriedades rurais analisadas. No período analisado a propriedade rural com melhor desempenho apresentou uma média de 48 matrizes em lactação (das raças Jersey e Holandesa), possui 50 hectares de terra direcionados para a atividade leiteira, a média de produção foi de 24 litros de leite por matriz ao dia,receita de $\mathrm{R} \$ 1,36$ por litro de leite, gerando uma receita média de $\mathrm{R} \$ 48.180,48$ por mês, os custos de produção somaram $\mathrm{R} \$ 17.915,67$ por mês, comlucro médio mensal de $\mathrm{R} \$ 30.264,81$. Já a propriedade com menor desempenho possui uma média de 9,6 litros de leite por matriz ao dia, receita de $\mathrm{R} \$ 0,95$ por litro de leite, gerando uma receita média mensal de $\mathrm{R} \$ 1.115,39$, os custos de produção totalizaram $\mathrm{R} \$ 685,33$ por mês, com lucro médio mensal de $\mathrm{R} \$ 430,06$. De modo geral, os resultados demonstraram que as atividades desenvolvidas nas propriedades rurais estudadas são rentáveis economicamente e contribuem com a geração de caixa e renda das famílias, evidenciando a importância da contabilidade e da análise dos custos no meio rural.
\end{abstract}

Silvana Dalmutt Kruger

Universidade Comunitária da Região de Chapecó

silvanak@unochapeco.edu.br

Danieli Ferreira

Universidade Comunitária da Região de Chapecó

danieli.ferreira@unochapeco.edu.br

Sérgio Murilo Petri

Universidade Federal de Santa Catarina

smpetri@gmail.com

Recebido em: 14/09/2017. Aprovado em: 01/04/2020.

Avaliado pelo sistema double blind review

Avaliador científico: Elisa Reis Guimarães

\begin{abstract}
The objective of this study was to compare indicators of economic and financial performance of dairy production in rural properties of Formosa do Sul-SC. Methodologically the research is characterized as descriptive carried out by means of survey, with quantitative analysis. Based on the identification of the patrimony, costs and revenues of the dairy activity, the main performance indicators of the 30 rural properties analyzed were identified. In the analyzed period, the rural property with the best performance showed an average of 48 matings in lactation (of the Jersey and Dutch breeds), it has 50 hectares of land directed to the milk activity, the average production was 24 liters of milk per day, revenue of $\mathrm{R} \$ 1,36$ per liter of milk, generating an average revenue of $\mathrm{R} \$ 48.180,48$ per month, production costs totaled R $\$ 17.915,67$ per month, with an average monthly profit of $\mathrm{R} \$ 30.264,81$. On the other hand, the lowest performance property has an average of 9.6 liters of milk per matrix per day, a revenue of $\mathrm{R} \$ 0,95$ per liter of milk, generating an average monthly revenue of R $\$ 1.115,39$, production costs totaled $\mathrm{R} \$ 685,33$ per month, with an average monthly income of $\mathrm{R} \$ 430,06$. In general, the results showed that the activities carried out on the rural properties studied are economically profitable and contribute to the generation of cash and income of families, highlighting the importance of accounting and cost analysis in the rural environment.
\end{abstract}

Palavras-chave: Atividade Leiteira. Contabilidade Rural. Análise Econômico-Financeiro.

Keywords: Milk Activity. Rural Accounting. Economic-Financial Analysis.

\section{INTRODUÇÃ̃O}

Entre os diversos segmentos econômicos, é notório que o agronegócio do leitetem destaque no setor agropecuário brasileiro. No Brasil, a produção leiteira vem crescendo e se destacando como uma das atividades mais tradicionais do meio rural, desempenhando um relevante papel social, principalmente na geração de empregos. Conforme dados da Empresa Brasileira de Pesquisa 
Agropecuária (EMBRAPA, 2019), 99\% dos municípios brasileiros desenvolvem a atividade leiteira, em 2016 o faturamento foi de R $\$ 67$ bilhões, considerando duas mil indústrias/laticínios legalizados, 1,3 milhões de produtores de leite e cerca de 4 milhões de trabalhadores no segmento.

A produção de leite brasileira foi de 33,5 bilhões de litros em 2017, sendo que $35,7 \%$ foram oriundos da região Sul, a produção de Santa Catarina atingiu 2,980 bilhões de litros em 2017, o que representa um crescimento de $149 \%$ em relação a produção de 1,193 bilhões de litros produzidos em 2002 (EMBRAPA, 2019).

Dettmer e Silva (2015), salientam que a produção leiteira é considerada uma importante estratégia de renda para o pequeno agricultor familiar e uma alternativa para o desenvolvimento de muitas regiões brasileiras. Brand et al. (2014), destacam que além da produção leiteira ter participação na formação de emprego e de renda, ela proporciona a fixação do homem no campo.

No contexto do desenvolvimento da cadeia produtiva leiteira, Spers, Wright e Amedomar (2013), evidenciam oportunidades e nichos de mercado ponderando o desenvolvimento do cooperativismo, indicando que as cooperativas serão cada vez mais focadas no fornecimento, na qualidade da matériaprima e na gestão dos produtores, enquanto a indústria será responsável pelo processamento, transformação e comercialização do leite.

Bonamigo, Ferenhof e Forcellini (2017), destacam que transformações no agronegócio brasileiro nos últimos anos, têm exigido dos gestores rurais maior controle e gestão no acompanhamento dos impactos dos processos produtivos, no sentido de acompanhar e gerenciar a sustentabilidade das atividades desenvolvidas no meio rural.

Neste contextose inserea contabilidade rural, como instrumento de mensuração, apoio, planejamento e controle das atividades desenvolvidas no meio rural. A contabilidade rural surgiu pela necessidade de controlar o patrimônio e possibilitar o acompanhamento dos resultados das atividades rurais, analisando os investimentos realizados (CREPALDI, 2011; ZANIN, BAGATINI, 2012). Com as exigências que o mercado consumidor impõe, é fundamental que o produtor tenha conhecimento da real situação da sua propriedade e dos resultados obtidos com as atividades desenvolvidas (DAL MAGRO et al., 2013; KRUGER et al., 2014).

Para que a propriedade rural possa alcançar os resultados desejados, torna-se relevante tomar possedas informações contábeis para auxiliar no processo de tomada de decisão e planejamento dos negócios, bem como da análise de desempenho econômico e financeiro dos resultados entre as atividades rurais (GOLLO et al., 2015). A análise de desempenho tem por objetivofornecer informaçõesque permitam quantificar a rentabilidade do empreendimento, auxiliar natomada de decisões para um bom andamento da propriedade e possibilitar o ajustedos desvios que prejudicam o desempenho dos negócios (GONZAGA et al., 2015).

Analisar o desempenho das propriedades rurais é essencial para a gestão das atividades. Com a utilização de indicadores de desempenho é possível acompanhar o processo das atividades desenvolvidas e atingir os objetivos desejados, com informações precisas do processo produtivo, contribuindo assim, no planejamento e controle do desempenho das propriedades rurais(GONZAGA et al., 2015; PIOVESANI, BORTOLUZZI, SILVA 2015).

Estudos correlatos como os deSouza et al. (2011), Lopes, Santos e Carvalho (2012), Sena et al. (2013), Duarte, Ferri e Honorato (2014), Gonçalves et al. (2014), Costa et al. (2015), Gollo et al. (2015), evidenciam a importância da análise dos resultados e do uso de medidas de desempenho econômico e financeiro para o acompanhamento da produção leiteira. Neste sentido,o presente estudo tem como objetivo, comparar indicadores de desempenho econômico-financeiro da produção leiteira em propriedades rurais de Formosa do Sul - SC.

Justifica-se a relevância da pesquisa considerando a importância da produção leiteira para o município de Formosa do Sul-SC,bem como pelo contexto do desenvolvimento a partir da agricultura familiar, neste aspecto a produção leiteira torna-se para muitas famílias a principal fonte de renda. Assim, o estudo objetivou identificar medidas e indicadores que contribuam na análise dos resultados e acerca do desempenho da produção realizada. Destaca-se também, a importância do uso da contabilidade para a gestão e controle das atividades rurais, principalmente para análise econômica e financeira, visando o equilíbrio e a gestão das propriedades rurais (VIANA; COSTA; SANTOS, 2014).

O estudo está estruturado em cinco seções, iniciando-se com uma breve introdução. Na segunda seção, aborda-se a importância da contabilidade rural na gestão dos negócios, bem como da utilizaçãode indicadores de desempenho para análise da produção leiteira, além de estudos anteriores ao tema de pesquisa.Na terceira seção, 
contemplam-se os procedimentos metodológicos da pesquisa. Na quarta seção, apresentam-se os resultados e as análises do estudo realizado e na quinta seção, as considerações finais da pesquisa.

\section{REVISÃO DA LITERATURA}

Neste capítulo, aborda-se a importância da contabilidade rural na gestão dos negócios rurais, os indicadores de desempenho da produção leiteira e alguns estudos correlatos relacionados à temática estudada.

\subsection{A Importância da Contabilidade Rural na Gestão dos Negócios Rurais}

Entende-se por contabilidade como a ciência do patrimônio, que temcomo objetivo principal oferecer informações úteis, confiáveis e oportunas que permitam ao usuário a obtenção de informações econômicas e financeiras acerca da entidade e que possibilitam o auxílio na tomada de decisão, atendendo pessoas físicas e jurídicas (MAZZIONI; DEDONATTO; GALANTE, 2012; MARION, 2012).

A contabilidade rural é uma importante ferramenta degestão dos negócios rurais, por meio dela é possível oferecer informaçõespara a tomada de decisões, durante a execução e o controle das operações das propriedades rurais, considerando sua finalidade deregistrar, controlar e planejar o patrimônio das entidades rurais, permitindo a análise dos resultados das atividades (CREPALDI, 2011; VIANA; COSTA; SANTOS, 2014).

Um dos principais sistemas de controle e informação das empresas rurais é a contabilidade rural, um instrumento de função administrativa, que tem a finalidadede orientar as operações exercidas nas atividades rurais, apurar o desempenho econômicofinanceiro de cada atividade, apoiar os processos de decisões da produção, das vendas e dos investimentos, auxiliar no controle das despesas pessoais do proprietário e de sua família, nasdespesase custos das atividades rurais de forma individual, no controle das transações financeiras, na comparabilidade dos resultados e com informações para a declaração do imposto de renda (CREPALDI, 2011).

A contabilidade rural possibilita o uso da informação contábil como ferramenta para a administração da propriedade e dos negócios, mas para que se alcance bons resultados no processo da gestão, faz-senecessárioà utilização de controles e o planejamento das decisões. Oprodutor rural precisa de controle das atividades e planejamentoda produção, observando e comparando custos de produção e resultados obtidos (GONÇALVES et al., 2014).

Para garantir a permanência dos produtores na atividade rural, é necessário adotar novos recursos e tecnologias adequadas possibilitando a diminuição dos custos (KRUGER et al., 2018; SABBAG; COSTA, 2015). A contabilidade rural utiliza-se de técnicas e metodologias da contabilidade de custos, servindo como instrumento de controle e planejamento das atividades, transmitindo informações que contribuem com o processo decisório. $\mathrm{O}$ controle tem a função de passar informações para o planejamento, ou seja, interpretar as principais atividades da propriedade a fim de averiguar se as ações previstas foram executadas, a partir da análise de informações do passado, do presente e as previsões do futuro, podeseidentificar as metas desejadas (GOLLO et al., 2015).

A contabilidade de custos aplicada ao contexto das propriedades rurais tem um importante papel como ferramenta de apoio na gestão, permitindo ao proprietário rural fazer a avaliação financeira e econômica, comparar a rentabilidade, identificar os fatores de produção e manter o controle do desempenho econômico, financeiro e patrimonial das atividades desenvolvidas (COSTA et al., 2015).

Nos negócios rurais, como em qualquer ramo de negócio, é fundamental controlar os custos das atividades, torna-se indispensável que os gestores conheçam os custos das atividades desenvolvidas para avaliar o desempenho dos custos frente às receitas atingidas. Se os negócios não tiverem controle, não permitem a análise e decisões adequadas (ZANINet al., 2013; KRUGER et al., 2017). Ter informação dos gastos torna-se importante para a administração da propriedade rural, pois a falta de conhecimento dos resultadospode diminuir o desempenho das atividades, além disso, pode acarretar investimentos desnecessários e redução da produtividade (VIANA; COSTA; SANTOS, 2014).

Marion (2012) enfatiza a importância da contabilidade rural como fator de crescimento e sobrevivência para as propriedades. Neste sentido, podese ressaltar a importância da contabilidade como uma ferramenta essencial para apoiar, controlar e planejar as atividades desenvolvidas no meio rural.

\subsection{Indicadores de Desempenho da Produção Leiteira}

Os indicadores de desempenho são instrumentos de gestão essenciais nas atividades de monitoramento e 
avaliação das organizações, que permitem acompanhar, analisar, propor, solucionar, interferir ou mudar o rumo de um processo ou conjunto de atividades, visando atingir determinado objetivo (GONZAGA et al., 2015).

Piovesani, Bortoluzzi e Silva (2015), destacam que os indicadores de desempenho têm por objetivo fornecer informações que permitam acompanhar a situação econômica e financeira da propriedade, com informações precisas do processo produtivo, embasando a análise crítica dos resultados obtidos e do processo de tomada de decisão, contribuindo no planejamento e controle do desempenho.

Ghisellini et al. (2014), observaram a agregação de valor em sistema de produção leiteira entre duas propriedades rurais, uma na Itália e outra na Polônia, evidenciando como a autogeração de energia a partir da atividade leiteira pode contribuir com a redução dos custos e nos resultados da atividade, porém destacam que a sustentabilidade depende do uso equilibrado de todos os recursos (mão de obra, insumos, fertilização e matéria prima).

A evidenciação dos resultados e a análise de indicadores de sustentabilidade também são uma necessidade no meio rural, visando mensurar e analisar aspectos sociais, ambientais e econômico-financeiros, como no caso da produção leiteira (PALHARES; PEZZOPANE, 2015). A análise de indicadores de sustentabilidade da produção leiteira pode contribuir com a melhoria e utilização dos recursos, observando alternativas de agregar valor aos produtores rurais e menores impactos ambientais (TICHENOR et al., 2017).

Ao analisar sistemas de produção leiteira como o free-stall por exemplo, é possível identificar que investimentos em instalações físicas, no conforto do plantel, bem como nas características da alimentação dos animais também podem representar maiores ganhos aos produtores rurais, assim como os investimentos em sistemas de resfriamento, limpeza e trato (BEWLEY; PALMER; JACKSON-SMITH, 2001).

Para medir o desempenho da produção leiteira, alguns autores utilizam fórmulas que contribuem significativamente no controle e gestão da propriedade rural. A partir da elaboração e gestão dos indicadores de desempenho, eles podem ser direcionados para o monitoramento da evolução dos resultados e servir como referência para o processo de tomada de decisão (LOPES, SANTOS, CARVALHO, 2012; CANDIDO et al., 2015). Lopes, Santos e Carvalho (2012) destacam que o uso de indicadores, permite diagnosticar o desempenho das atividades e por meio deles, é possível fazer um levantamento de informações que possam gerar intervenções a fim de aumentar a sua eficiência, ou seja, buscar a redução dos custos das atividades e aumentar o faturamento. Os indicadores de desempenho facilitam a compreensão das atividades e fluxos operacionais da produção leiteira (GONZAGA et al., 2015). Além disso, contribuem para a análise e controle das atividades desenvolvidas nas propriedades rurais, auxiliando os gestores no processo de tomada de decisões.

$\mathrm{Na}$ atividade da produção leiteira, a análise dos indicadores de desempenho econômico e financeiro é de grande destaque. É através dos indicadores, que gestores de propriedades poderão aumentar seus rendimentos, reduzir seus custos e aumentar suas receitas (LOPES; SANTOS; CARVALHO, 2012).

No Quadro 1, observam-se alguns indicadores que podem ser utilizados para medir o desempenho da produção leiteira.

Observa-se no Quadro 1, alguns dos indicadores que são utilizados para medir o desempenho econômicofinanceiro da produção leiteira. Estes indicadores permitem umacompanhamento do alcance das metas dos produtores, a identificação dos avanços, melhorias de qualidade, correção de problemas e as necessidades de mudança da propriedade.

\subsection{Estudos Correlatos}

Esta seção destacam-se estudos com abordagens correlatas, como os de Souza et al. (2011), Lopes, Santos e Carvalho (2012), Sena et al. (2013), Duarte, Ferri e Honorato (2014), Gonçalves et al. (2014), Costa et al. (2015), Gollo et al. (2015), à temática investigada, evidenciando os mais diversos resultados dos estudos realizados em concordância com o tema de pesquisa abordada.

O estudo de Souza et al. (2011) teve por objetivo analisar os custos de produção leiteira de10produtores da associação ASPRODIL, em Rondônia. Os resultados indicam duas formas de produtividade: vacas por hectare e litro por vaca/dia.Quanto ao resultado o melhor desempenho foi dado pelo produtor que obteve 4,89 vacas por hectare, quanto à produtividade o melhor resultado foi de 4,21 litros/vaca/dia. De forma geral, os produtores com menores custos operacionais, entre $\mathrm{R} \$ 200,00$ e $\mathrm{R} \$ 400,00$ por matriz, apresentaram menor produtividade entre 2 e 3 litros/vaca/dia. No que se refere aos custos de produção, 
de forma geral, o que está contribuindo para a ineficiência dos produtores são os gastos operacionais da atividade.

O estudo de Lopes, Santos e Carvalho (2012), comparou alguns indicadores econômicos de fazendas leiteiras das regiões centrais mineiras e sul/sudoeste de Minas Gerais, em regimes de semi-confinamento e de confinamento total. Os resultados demonstraram que, ao compararem os indicadores de eficiência econômica (margem bruta, margem líquida e resultado), os resultados foram positivos nos sistemas em semiconfinamento. A produtividade média de leite por vaca em lactação foi de R\$ 15,62 e R\$22,25 kg/vaca/dia, nos sistemas em semi-confinamento e confinamento total respectivamente. Já a produção de leite por hectare foi maior nos sistemas em confinamento total $(9.317,88 \mathrm{~kg} /$ ha/ano), pois apresentaram maior média de produção por animal e taxa de lotação, em comparação com a do sistema em semi-confinamento $(6.818,31 \mathrm{~kg} / \mathrm{ha} / \mathrm{ano})$. Por fim, na análise econômica, o sistema de produção em semi-confinamentoapresentouresultado positivo, viabilidade econômica e condições de produzir no curto, médio e longo prazo; enquanto o sistema de produção em confinamento apresentou margem bruta negativaindicando a descapitalização dos investimentos e o endividando dos produtores que atuam neste sistema de produção.

O estudo de Sena et al. (2013), avaliou o nível de desenvolvimento tecnológico de 176 produtores de leite dos municípios de Itaituba, Rurópolis, Trairão e Placas, do estado do Pará.Os resultados obtidos demonstraram que, em relação à classificação do nível tecnológico os produtores que detinham maior padrão tecnológico foram mais produtivos que os demais. Em relação à produtividade (litros/vaca/dia), o tempo de experiência dos produtores no desenvolvimento daatividade leiteira,

QUADRO 1 - Indicadores de desempenho da produção leiteira

\begin{tabular}{|c|c|c|c|}
\hline Indicadores & Conceito & Fórmula & Autor \\
\hline Litros de leite ao ano & Quantidade de litros de leite ao ano & Litros/ano & Souza et al. (2011) \\
\hline Matrizes leiteiras por hectare & Quantidade de matrizes por hectare & Vacas/hectare & Souza et al. (2011) \\
\hline Litro por vaca ao dia & Quantidade de litro por vaca ao dia & Litros/vaca/dia & $\begin{array}{l}\text { Souza et al. (2011) e } \\
\text { Sena et al. (2013) }\end{array}$ \\
\hline $\begin{array}{l}\text { Leite por matriz de ordenha por } \\
\text { ano }\end{array}$ & $\begin{array}{l}\text { Quantidade de leite por matriz de } \\
\text { ordenha por ano }\end{array}$ & Leite/vaca/ordenha/ano & $\begin{array}{l}\text { Duarte, Ferri e } \\
\text { Honorato (2014) }\end{array}$ \\
\hline Litros de leite vendido & Quantidade de litro de leite vendido & Litro/vendido & Golloet al. (2015) \\
\hline Lucro por litro de leite vendido & $\begin{array}{l}\text { Lucro por quantidade de litro de leite } \\
\text { vendido }\end{array}$ & Lucro/leite/vendido & Golloet al. (2015) \\
\hline $\begin{array}{l}\text { Despesa e receita obtida por } \\
\text { hectare }\end{array}$ & Margem bruta $(\mathrm{R} \$)$ por /hectare & $\mathrm{R} \$ /$ há & Gonçalves et al. (2014) \\
\hline Produtividade de leite por matriz & $\begin{array}{l}\text { Produtividade média de leite por matriz } \\
\text { ao dia }\end{array}$ & $\mathrm{kg} / \mathrm{vaca} / \mathrm{dia}$ & $\begin{array}{l}\text { Lopes, Santos e } \\
\text { Carvalho (2012) }\end{array}$ \\
\hline Leite por hectare ao ano & Produção de leite por hectare ao ano & $\mathrm{kg} / \mathrm{ha} / \mathrm{ano}$ & $\begin{array}{l}\text { Lopes, Santos e } \\
\text { Carvalho (2012) }\end{array}$ \\
\hline Litros de leite por matriz por dia & Quantidade de leite por matriz ao dia & Leite/vaca/dia & Candido et al. (2015) \\
\hline Receita bruta por hectare & Renda bruta por hectare & Renda bruta/ hectare & $\begin{array}{l}\text { Carlotto, Filippi e } \\
\text { Marcello (2011) }\end{array}$ \\
\hline Receita bruta por Litro & $\begin{array}{c}\text { Renda bruta por quantidade de litro de } \\
\text { leite }\end{array}$ & Renda bruta/litro & $\begin{array}{l}\text { Carlotto, Filippi e } \\
\text { Marcello (2011) }\end{array}$ \\
\hline Custo variável por litro de leite & $\begin{array}{l}\text { Custo variável por quantidade de litro } \\
\text { de leite }\end{array}$ & Custo variável /litro & $\begin{array}{l}\text { Carlotto, Filippi e } \\
\text { Marcello (2011) }\end{array}$ \\
\hline Lucro por hectare & Resultado mensal por hectare & Lucro/hectare & $\begin{array}{l}\text { Carlotto, Filippi e } \\
\text { Marcello (2011) }\end{array}$ \\
\hline Lucro por litro de leite & $\begin{array}{l}\text { Resultado mensal por quantidade } \\
\text { comercializada }\end{array}$ & Lucro /litro & $\begin{array}{l}\text { Carlotto, Filippi e } \\
\text { Marcello (2011) }\end{array}$ \\
\hline
\end{tabular}

Fonte: Elaborado pelosautores 
constatou-se que $81,82 \%$ trabalhavam,em média, 13 anos com a produção de leite, indicando que a experiência tinhaimpacto na adoção de mudanças tecnológicas na produção, especialmenteem uma área em que os produtores enfrentam sérios problemas de acessoà assistência técnica.

A pesquisa de Duarte, Ferri e Honorato (2014), teve por objetivo expor os principais problemas encontrados na cadeia produtiva da pecuária leiteira, principalmente a viabilidade econômica da atividade. Os resultados demonstraram vários problemas relacionados àprodução, no qual o prejuízo se faz mais constante que o lucro. Dentre eles, destacam-se: (i) o sistema extensivo (animais com produção de até 1.200 litros de leite/vaca/ordenha/ ano, alimentados a pasto); (ii) sistema semi-extensivo (produção varia entre 1.200 a 2.000 litros/vaca/ordenha/ ano, os animais são mantidos a pasto, mas recebem suplementação); (iii) sistema intensivo a pasto (animais com produção entre 2.000 e 4.500 litros/vaca/ordenha/ano, além do pastoreio em forragens recebem suplementação); e (iv) o sistema intensivo em confinamento (animais com produção a partir de 4.500 litros/vaca/ordenha/ ano, recebem no cocho toda a sua alimentação). Após levantamento, constataram que o sistema extensivo responde por $37,7 \%$ da produção nacional, apesar da baixa rentabilidade, ao passo que o sistema de confinamento é mantido por uma parcela de $0,1 \%$ dos produtores e é responsável por $4,6 \%$ da produção leiteira, evidenciando maior rentabilidade.

Gonçalves et al. (2014) realizaram a pesquisa em uma propriedade de gado leiteiro no município de Sales de Oliveira/SP, com o objetivo de demonstrar a importância da assistência técnica por meio da extensão rural na melhoria da atividade leiteira. Os resultados apontaram que o acompanhamento fez com que a produtividade em litros de leite produzido por hectare aumentasse e o volume anual de leite vendido passasse de 21.575 litros em 2009 para 32.402 em 2012, apresentando uma média de crescimento de $16,7 \%$ ao ano em litros de leite. No resultado da relação entre a despesa e a receita obtida, em 2009 a margem bruta era de R\$1.640,10 por hectare, já em 2011 passou para $R \$ 3.610,79$. A rentabilidade na propriedade teve um aumento da tecnificação e na medida em que melhoraram seus indicadores de produtividade, aumentou a margem bruta e taxa de retorno do capital investido.

Costa et al. (2015), analisaram os custos a partir da cadeia de valor do leite e derivados de um pequeno produtor leiteiro da região do Seridó, estado do Rio Grande do Norte.A pesquisa foi realizada através de uma metodologia descritiva, com estudo de caso e análise qualitativa. Os resultados obtidos demonstram um sistema de custeamento bastante limitado,o qual apresentou um prejuízo médio de $\mathrm{R} \$ 0,12$ por litro de leite vendido, com uma receita bruta média mensal de $\mathrm{R} \$$ $2.377,80$, o custo total médio mensal foi de $\mathrm{R} \$ 2.561,02$ e a produção média mensal foi de 1.552 litros de leite. Destacam que os pequenos produtores precisarão ir em busca de novos conhecimentos e alternativas eficientes e viáveis para conseguir avaliar melhor seus custos de produção.

O estudo de Golloet al. (2015) teve por objetivo comparar o resultado econômico e financeiro das atividades suinícola e leiteira, desenvolvidas numa entidade rural do município de Coronel Freitas - SC. Analisado o resultado financeiro do período, à atividade suinícolagerou margem positiva de $94,80 \%$ ou $\mathrm{R} \$ 12,84$ por suíno comercializado, no entanto, sob os aspectos contábeis a atividade apresenta um resultado de $\mathrm{R} \$ 1,97$ por suíno comercializado. Quanto à atividade leiteira, sob aspecto econômico, apresentou resultado líquido correspondente a $10,98 \%$ da receita operacional líquida, ou $\mathrm{R} \$ 0,07$ por litro de leite vendido, enquanto sob o aspecto financeiro, o resultado foi de $63,32 \%$ em relação à receita operacionallíquida ou $\mathrm{R} \$ 0,40$ de lucro por litro de leite vendido. Indicam que a atividade suinícola apresentou melhor desempenho econômico e financeiro, no entanto, renda da atividade leiteira também é representativa e viável.

De modo geral os resultados dos estudos realizados acerca da temática abordada, mesmo que desenvolvidas em diferentes contextos, evidenciam a importância da análise dos resultados da produção leiteira e do uso de medidas de desempenho econômico e financeiro, para melhoramentoda gestão das propriedades rurais e obtenção de informações que possam auxiliar na tomada de decisões.

\section{PROCEDIMENTOS METODOLÓGICOS}

As características da pesquisa, quanto àsua tipologiapode ser classificada considerando-se três enfoques, de acordo com Raupp e Beuren (2012): (i) quanto aos objetivos; (ii) quanto aos procedimentos e (iii) quanto à abordagem do problema.

Quanto aos objetivos, a pesquisa caracteriza-se como descritiva. Para Gil (2010), a pesquisa descritiva tem como objetivo principal identificar as características de determinada população, estabelecendo relação entre as variáveis no objeto de estudo analisado. 
Quanto aos procedimentos de investigação, o estudo é de levantamento, com aplicação de um questionário de pesquisa aplicado aos produtores rurais. A população do estudo compreende as propriedades rurais do município de Formosa do Sul - SC. De acordo com dados da Prefeitura Municipal de Formosa do Sul - SC (2016), atualmente 340 propriedades desenvolvem a atividade leiteira no município.A amostra do estudo foi aplicada em 30 propriedades rurais, em razão da acessibilidade e disponibilidade em contribuir com as informações ea fim decomparar os principais indicadores de desempenho econômico financeiro por elas apresentados.

Quanto à abordagem do problema, a pesquisa configura-se como quantitativa, baseadanas respostas coletadas a partir do questionário aplicado. Fachin (2005) indica que,a variável quantitativa é determinada em relação aos dados ou a proporção numérica, em termos gerais, é uma forma de identificar informações úteis para o estudo. O roteiro de questões utilizado foi adaptado do questionário de Kruger et al. (2014), para identificar as características das propriedades rurais, para o levantamento patrimonial adaptou-se o modelo de Kruger et al. (2017), e para as questões relacionadas à produção utilizou-se dos indicadores validados na revisão da literatura, conforme apresenta o Quadro 1 deste estudo.

Visando atingir os objetivos propostos pelo estudo, realizaram-se visitas junto a 30 propriedades rurais para a coleta de dados, buscando-se identificar seu patrimônio, suas receitas e despesas; e após a organização dos dados, foram elaboradas tabelas com o intuito de facilitar a compreensão do assunto e permitir a comparação e análise dos resultados. O período para a coleta e análise dos dados correspondeu ao mês de novembro/2016 a janeiro/2017, referente à produção leiteira do último trimestre de 2016.

Desta forma, metodologicamente a pesquisa caracteriza-se como descritiva, realizada por meio de análise de dados predominantemente quantitativa, elaborada a partir de levantamento, objetivando apresentar indicadores de desempenho econômico-financeiro da produção leiteira em propriedades rurais do município de Formosa do Sul - SC.

\section{ANÁLISE E INTERPRETAÇÃO DOS RESULTADOS}

A partir da coleta de dados executadas por meio da aplicação de questionários, buscou-se identificar os principais indicadores de desempenho da produção leiteira. Inicialmente buscou-se analisar as características dos respondentes, conforme a Tabela 1 .

TABELA 1 - Identificação dos Produtores Rurais

\begin{tabular}{|c|c|c|}
\hline Quantidade de pessoas & $\begin{array}{c}\text { Frequência } \\
\text { Absoluta }\end{array}$ & $\begin{array}{c}\text { Frequência } \\
\text { Relativa (\%) }\end{array}$ \\
\hline Feminino & 38 & 49 \\
\hline Masculino & 40 & 51 \\
\hline Sub Total & 78 & 100 \\
\hline Idade & $\begin{array}{c}\text { Frequência } \\
\text { Absoluta }\end{array}$ & $\begin{array}{c}\text { Frequência } \\
\text { Relativa (\%) }\end{array}$ \\
\hline Até 35 anos & 28 & 36 \\
\hline De 36 a 46 anos & 17 & 22 \\
\hline Acima de 47 anos & 33 & 42 \\
\hline Sub Total & 78 & 100 \\
\hline Escolaridade & $\begin{array}{c}\text { Frequência } \\
\text { Absoluta }\end{array}$ & $\begin{array}{c}\text { Frequência } \\
\text { Relativa (\%) }\end{array}$ \\
\hline Ensino Básico Incompleto & 33 & 42 \\
\hline Ensino Básico Completo & 5 & 6 \\
\hline Ensino Médio Incompleto & 7 & 9 \\
\hline Ensino Médio Completo & 27 & 35 \\
\hline Ensino Superior Incompleto & 3 & 4 \\
\hline Ensino Superior Completo & 3 & 4 \\
\hline Sub Total & 78 & 100 \\
\hline Tempo de atuação & $\begin{array}{c}\text { Frequência } \\
\text { Absoluta }\end{array}$ & $\begin{array}{c}\text { Frequência } \\
\text { Relativa (\%) }\end{array}$ \\
\hline Até 10 anos & 5 & 17 \\
\hline De 11 a 20 anos & 10 & 33 \\
\hline De 21 a 30 anos & 8 & 27 \\
\hline Acima de 31 anos & 7 & 23 \\
\hline Sub Total & 30 & 100 \\
\hline
\end{tabular}

Fonte: Dados da pesquisa

Na Tabela 1, observa-se que $51 \%$ dos produtores ruraisestãorepresentados por homens e $49 \%$ por mulheres, onde que, das 30 propriedades analisadas, as mesmas apresentaram uma soma de 78 pessoas (homens e mulheres) atuando na atividade leiteira. Verifica-se que $58 \%$ dos produtores possuem até 46 anos de idade e $42 \%$ representamuma faixa etária acima de 47 anos de idade. Nota-se que, $42 \%$ dos produtores rurais possuem ensino básico incompleto e $35 \%$ dos proprietários possuem ensino médio completo. Constata-se também que $60 \%$ dos 
produtores atuam na atividade leiteira hámais de10 anos na atividade e outros $23 \%$ possuem acima de 30 anos de atuação no meio rural.

Posteriormente buscou-se identificar as características das propriedades rurais pesquisadas, conforme apresenta a Tabela 2.

TABELA 2 - Características das propriedades rurais

\begin{tabular}{ccc}
\hline Mão de Obra & $\begin{array}{c}\text { Frequência } \\
\text { Absoluta }\end{array}$ & $\begin{array}{c}\text { Frequência } \\
\text { Relativa (\%) }\end{array}$ \\
\hline Familiar & 29 & 97 \\
Terceirizada & 1 & 3 \\
Sub Total & 30 & 100 \\
\hline Principal fonte de & Frequência & Frequência \\
renda & Absoluta & Relativa (\%) \\
\hline Sim & 27 & 90 \\
Não & 3 & 10 \\
Sub Total & 30 & 100 \\
\hline Tamanho (hectares) & Frequência & Frequência \\
\hline Até 20 hectares & 11 & Relativa (\%) \\
De 21 a 30 Hectares & 13 & 37 \\
Acima de 31 & 6 & 43 \\
hectares & 30 & 100 \\
Sub Total & &
\end{tabular}

Fonte: Dados da pesquisa

Os resultados apresentados na Tabela 2 indicam que, $97 \%$ das propriedades rurais possuemmão de obra familiar na atividade leiteira, sendo que para $90 \%$ a atividade leiteira é a principalfonte de renda. Quanto ao tamanho das propriedades rurais $37 \%$ possuem até 20 hectares de terra e outros $43 \%$ possuem entre 21 a 30 hectares, evidenciando característica de propriedades rurais de pequeno porte.

$\mathrm{Na}$ sequência questionou-se os produtores rurais em relação às principais características do plantel das matrizes leiteiras e a forma de comercialização do leite, conforme apresenta-se na Tabela 3. Os resultados apresentados na Tabela 3 evidenciam que, $60 \%$ das propriedades rurais possuem até 20 novilhas e/ou bezerras e outras $33 \%$ possuem entre 21 a 30 novilhas e/ou bezerras. Verifica-se que $60 \%$ dos produtores possuem uma mistura de raças de matrizes, Jersey e Holandesa.
TABELA 3 - Características do plantel de matrizes leiteiras

\begin{tabular}{|c|c|c|}
\hline $\begin{array}{c}\text { Quantidade de } \\
\text { novilhas e bezerras }\end{array}$ & $\begin{array}{c}\text { Frequência } \\
\text { Absoluta }\end{array}$ & $\begin{array}{c}\text { Frequência } \\
\text { Relativa (\%) }\end{array}$ \\
\hline Até 20 novilhas/bezerras & 18 & 60 \\
\hline $\begin{array}{c}\text { De } 21 \text { a } 30 \text { novilhas/ } \\
\text { bezerras }\end{array}$ & 10 & 33 \\
\hline $\begin{array}{c}\text { Acima de } 31 \text { novilhas/ } \\
\text { bezerras }\end{array}$ & 2 & 7 \\
\hline Sub Total & 30 & 100 \\
\hline Raça matrizes & $\begin{array}{l}\text { Frequência } \\
\text { Absoluta }\end{array}$ & $\begin{array}{c}\text { Frequência } \\
\text { Relativa (\%) }\end{array}$ \\
\hline Jersey & 8 & 27 \\
\hline Holandesa & 4 & 13 \\
\hline Jersey e Holandesa & 18 & 60 \\
\hline Sub Total & 30 & 100 \\
\hline Genética & $\begin{array}{l}\text { Frequência } \\
\text { Absoluta }\end{array}$ & $\begin{array}{c}\text { Frequência } \\
\text { Relativa (\%) }\end{array}$ \\
\hline Natural & 8 & 27 \\
\hline Inseminação & 14 & 47 \\
\hline Ambas & 8 & 27 \\
\hline Sub Total & 30 & 100 \\
\hline Tipo de ordenha & $\begin{array}{l}\text { Frequência } \\
\text { Absoluta }\end{array}$ & $\begin{array}{c}\text { Frequência } \\
\text { Relativa (\%) }\end{array}$ \\
\hline Mecânica & 21 & 70 \\
\hline Canalizada & 9 & 30 \\
\hline Sub Total & 30 & 100 \\
\hline Comercialização do leite & $\begin{array}{l}\text { Frequência } \\
\text { Absoluta }\end{array}$ & $\begin{array}{c}\text { Frequência } \\
\text { Relativa (\%) }\end{array}$ \\
\hline Laticínios & 26 & 87 \\
\hline Cooperativas & 4 & 13 \\
\hline Sub Total & 30 & 100 \\
\hline $\begin{array}{c}\text { Sistema de exploração } \\
\text { leiteira }\end{array}$ & $\begin{array}{l}\text { Frequência } \\
\text { Absoluta }\end{array}$ & $\begin{array}{c}\text { Frequência } \\
\text { Relativa (\%) }\end{array}$ \\
\hline Extensivo & 1 & 3 \\
\hline Semi-extensivo & 20 & 67 \\
\hline Intensivo a pasto & 9 & 30 \\
\hline $\begin{array}{c}\text { Intensivo a } \\
\text { Confinamento }\end{array}$ & 0 & 0 \\
\hline Sub Total & 30 & 100 \\
\hline
\end{tabular}

Fonte: Dados da pesquisa

Observa-se que $47 \%$ dos produtores utilizam a inseminação para o processo de recria. Evidencia-se 
que $70 \%$ das propriedades fazem uso de ordenha mecânica para manuseio da atividade leiteira e apenas $30 \%$ utilizam a ordenha canalizada. Referente à comercialização do leite $87 \%$ dos proprietários realizam a entrega para laticínios. E quanto ao tratamento e manuseio dos animais, constatou-se que $67 \%$ das propriedades rurais fazem uso do sistema de exploração semi-extensivo, sistema este em que os animais são mantidos a pasto, mas recebem suplementação em períodos do ano.

Outras questões da investigação vinculadas à pesquisa abordaram às características dos investimentos na atividade leiteira de cada propriedade rural, conforme destaca-se na Tabela 4.

TABELA 4 - Características dos investimentos da atividade leiteira

\begin{tabular}{|c|c|c|}
\hline $\begin{array}{c}\text { Tempo de construção de } \\
\text { galpões }\end{array}$ & $\begin{array}{l}\text { Frequência } \\
\text { Absoluta }\end{array}$ & $\begin{array}{c}\text { Frequência } \\
\text { Relativa (\%) }\end{array}$ \\
\hline Até 10 anos & 12 & 40 \\
\hline De 11 a 20 anos & 10 & 33 \\
\hline Acima de 21 anos & 8 & 27 \\
\hline Sub Total & 30 & 100 \\
\hline Investimento propriedade & $\begin{array}{l}\text { Frequência } \\
\text { Absoluta }\end{array}$ & $\begin{array}{c}\text { Frequência } \\
\text { Relativa (\%) }\end{array}$ \\
\hline até $\mathrm{R} \$ 19.999,99$ & 12 & 40 \\
\hline $\begin{array}{c}\text { De } \mathrm{R} \$ 20.000,00 \text { a } \mathrm{R} \$ \\
39.999,99\end{array}$ & 12 & 40 \\
\hline Acima de $\mathrm{R} \$ 40.000,00$ & 6 & 20 \\
\hline Sub Total & 30 & 100 \\
\hline Investimento cada matriz & $\begin{array}{l}\text { Frequência } \\
\text { Absoluta }\end{array}$ & $\begin{array}{c}\text { Frequência } \\
\text { Relativa (\%) }\end{array}$ \\
\hline Até R \$ 2.499,99 & 9 & 30 \\
\hline $\begin{array}{c}\text { De } \mathrm{R} \$ 2.500,00 \text { até } \mathrm{R} \$ \\
3.499,00\end{array}$ & 13 & 43 \\
\hline Acima de $\mathrm{R} \$ 3.500,00$ & 8 & 27 \\
\hline Sub Total & 30 & 100 \\
\hline $\begin{array}{l}\text { Financiamentos/ } \\
\text { empréstimos ativos }\end{array}$ & $\begin{array}{c}\text { Frequência } \\
\text { Absoluta }\end{array}$ & $\begin{array}{c}\text { Frequência } \\
\text { Relativa (\%) }\end{array}$ \\
\hline Não possui & 16 & 53 \\
\hline Até R\$10.999,99 & 4 & 13 \\
\hline $\begin{array}{c}\text { De R\$ } 11.000,00 \text { até } \mathrm{R} \$ \\
30.999,99\end{array}$ & 1 & 3 \\
\hline Acima de $\mathrm{R} \$ 31.000,00$ & 9 & 30 \\
\hline Sub Total & 30 & 100 \\
\hline
\end{tabular}

Fonte: Dados da pesquisa
$\mathrm{Na}$ Tabela 4, os resultados indicam que $40 \%$ das propriedades rurais possuem instalações (galpões, sala de ordenha, estrebarias) construídas há até 10 anos, 33\% entre 11 a 20 anos e $27 \%$ das propriedades possuem seus imobilizados a mais de 21 anos. Referente aos investimentos, $40 \%$ dos produtores investiram até R $\$ 19.999,99$ e $60 \%$ dos produtores investiram acima de $\mathrm{R} \$ 20.000,00$.

Evidencia-se que $43 \%$ das propriedades ruraisgastaram entre R\$ 2.500,00 a R\$ 3.499,99 na aquisição de cada matriz. E observa-se ainda que, das 30 propriedades rurais analisadas, 16 delas não possuem nenhum financiamento e/ou empréstimo relacionado à atividade leiteira e outras 14 propriedades rurais possuem endividamento relacionado à atividade.

A pesquisa ainda indagou sobre a receita por litro de leite vendido, os custos de produção, a vida útil estimada dos animais e das instalações, visando identificar os resultados. Apresenta-se a evidenciação dos resultados de cada propriedade ruralna Tabela 5 .

Observa-se na Tabela 5 a evidenciação dos resultados de cada propriedade rural. Observa-se a quantidade de matrizes em lactação, a quantidade média de litros de leite produzidos por matriz ao dia, a média da receita por litro de leite, a receita total, os custos relacionados à atividade leiteira, as depreciações das matrizes e das instalações, e consequentemente o lucro identificado em reais $(R \$)$ e em percentual (\%). Destaca-se que não foi identificada nenhuma propriedade rural com prejuízo.

Verifica-se que das 30 propriedades rurais analisadas, a quantidade de matrizes em lactação varia entre 4 a 48 matrizes por propriedade rural. A quantidade média de litros produzidos de leite por matriz ao dia varia entre 8,9 a 24 litros, destes, a média da receita por litro de leite varia em torno de $\mathrm{R} \$ 0,95$ a $\mathrm{R} \$ 1,36$, a receita acompanha a quantidade de matrizes e de litros de leite produzidos em cada propriedade.

Da receita total (preço por litro versus quantidade de leite vendido) por estabelecimento, observou-se que houve uma variação entre R\$ 1.115,39 a R\$ 48.180,48. Evidenciou-se que o custo total da atividade leiteira oscilou de $\mathrm{R}$ \$ 685,33 a R\$ 17.195,67. Referente às depreciações das matrizes e das instalações, observou-se que a depreciação mensal tem variação de $\mathrm{R} \$ 141,67$ a $\mathrm{R} \$ 2.750,00$. O lucro da atividade leiteira foi de $\mathrm{R} \$ 430,06$ a $\mathrm{R} \$ 30.264,81$ ao mês, representando uma variação de $24,05 \%$ a 70,22\%.

$\mathrm{Na}$ Tabela 5 verifica-se a evidenciação dos resultados de cada propriedade, onde pode-se observar que, as que apresentavam menor número de matrizes, o preço recebido na venda por litro também foi menor, e 
consequentemente, o lucro por litro também foi menor, mas isso não aponta que a margem de lucro tenha sido menor em comparação com estabelecimentos com maior número de matrizes em lactação.Os resultados do estudo vão ao encontro da pesquisa de Sabbag e Costa (2015), em que destacamque,a produção em litros de leite e o preço recebido pela distribuição do leite caracterizam variáveis de maior expressividade quando comparado ao lucro.
Evidenciam-se na Tabela 6 os indicadores de desempenho da atividade leiteira.Nela é possível observar a quantidade de litros de leite anual de cada propriedade rural, a receita por litro, a receita por matriz, a receita por hectare, o lucro por litro, o lucro por matriz, o lucro por hectare e a remuneração média da mão de obra de cada proprietário que atua na atividade leiteira.

TABELA 5 - Evidenciação dos resultados de cada propriedade rural por mês

\begin{tabular}{|c|c|c|c|c|c|c|c|c|}
\hline Propriedade & $\begin{array}{c}\text { Matrizes } \\
\text { em lactação }\end{array}$ & $\begin{array}{c}\text { Litros leite } \\
\text { matriz ao dia }\end{array}$ & $\begin{array}{c}\text { Média receita } \\
\text { litro (RS) }\end{array}$ & $\begin{array}{c}\text { Receita } \\
\text { total (RS) }\end{array}$ & Custo (R\$) & $\begin{array}{c}\text { Depreciações } \\
\text { (R\$) }\end{array}$ & $\begin{array}{c}\text { Lucro } \\
\text { (R\$) }\end{array}$ & $\begin{array}{c}\text { Lucro } \\
(\%)\end{array}$ \\
\hline 1 & 11 & 13 & 1,07 & $4.787,29$ & $2.650,00$ & 630,21 & $1.507,08$ & 31,48 \\
\hline 2 & 12 & 9 & 1,03 & $3.422,88$ & $2.163,33$ & 495,83 & $1.259,55$ & 36,80 \\
\hline 3 & 9 & 9 & 1,00 & $2.484,00$ & $1.694,33$ & 319,79 & 789,67 & 31,79 \\
\hline 4 & 11 & 10 & 1,05 & $3.525,68$ & $2.365,00$ & 387,50 & $1.160,68$ & 32,92 \\
\hline 5 & 15 & 11 & 1,07 & $5.432,35$ & $2.830,67$ & 681,25 & $2.601,68$ & 47,89 \\
\hline 6 & 13 & 10 & 1,09 & $4.345,47$ & $2.141,67$ & 415,63 & $2.203,80$ & 50,71 \\
\hline 7 & 22 & 14 & 1,11 & $10.517,17$ & $3.236,00$ & 727,08 & $7.281,17$ & 69,23 \\
\hline 8 & 34 & 18 & 1,20 & $22.584,84$ & $9.313,00$ & $1.687,50$ & $13.271,84$ & 58,76 \\
\hline 9 & 11 & 11 & 1,02 & $3.773,18$ & $2.865,67$ & 378,13 & 907,52 & 24,05 \\
\hline 10 & 14 & 10 & 1,07 & $4.123,14$ & $1.672,33$ & 529,17 & $2.450,81$ & 59,44 \\
\hline 11 & 20 & 15 & 1,17 & $10.767,00$ & $4.860,00$ & $1.041,67$ & $5.907,00$ & 54,86 \\
\hline 12 & 26 & 17 & 1,16 & $15.774,98$ & $5.716,00$ & $1.052,08$ & $10.058,98$ & 63,77 \\
\hline 13 & 26 & 18 & 1,12 & $16.077,36$ & $5.080,00$ & 864,58 & $10.997,36$ & 68,40 \\
\hline 14 & 22 & 18 & 1,25 & $15.178,68$ & $4.815,00$ & 979,17 & $10.363,68$ & 68,28 \\
\hline 15 & 20 & 17 & 1,21 & $12.581,13$ & $5.500,33$ & 966,67 & $7.080,80$ & 56,28 \\
\hline 16 & 18 & 13 & 1,11 & $7.683,00$ & $2.919,33$ & 543,75 & $4.763,67$ & 62,00 \\
\hline 17 & 18 & 11 & 1,12 & $6.823,08$ & $2.267,67$ & 516,67 & $4.555,41$ & 66,76 \\
\hline 18 & 16 & 11 & 1,02 & $5.522,88$ & $2.314,00$ & 545,83 & $3.208,88$ & 58,10 \\
\hline 19 & 15 & 13 & 1,21 & $7.235,80$ & $2.963,67$ & 409,38 & $4.272,13$ & 59,04 \\
\hline 20 & 16 & 22 & 1,28 & $13.820,69$ & $4.639,67$ & 916,67 & $9.181,03$ & 66,43 \\
\hline 21 & 4 & 10 & 0,95 & $1.115,39$ & 685,33 & 141,67 & 430,06 & 38,56 \\
\hline 22 & 18 & 14 & 1,09 & $8.399,16$ & $2.755,33$ & 575,00 & $5.643,83$ & 67,20 \\
\hline 23 & 13 & 11 & 1,05 & $4.605,08$ & $2.140,00$ & 569,79 & $2.465,08$ & 53,53 \\
\hline 24 & 17 & 12 & 1,15 & $7.173,32$ & $2.202,33$ & 647,92 & $4.970,99$ & 69,30 \\
\hline 25 & 26 & 15 & 1,20 & $14.371,50$ & $4.780,00$ & 883,33 & $9.591,50$ & 66,74 \\
\hline 26 & 48 & 24 & 1,36 & $48.180,48$ & $17.915,67$ & $2.750,00$ & $30.264,81$ & 62,82 \\
\hline 27 & 16 & 12 & 1,13 & $6.654,08$ & $3.080,67$ & 329,17 & $3.573,41$ & 53,70 \\
\hline 28 & 28 & 22 & 1,30 & $24.512,69$ & $7.300,00$ & $1.366,67$ & $17.212,69$ & 70,22 \\
\hline 29 & 12 & 9 & 1,03 & $3.368,65$ & $1.466,00$ & 373,96 & $1.902,65$ & 56,48 \\
\hline 30 & 15 & 10 & 1,09 & $4.928,91$ & $1.806,67$ & 373,96 & $3.122,24$ & 63,35 \\
\hline Total & 546 & 407 & 33,71 & $299.769,88$ & $116.139,67$ & $22.100,00$ & $183.000,00$ & - \\
\hline
\end{tabular}

Fonte: Dados da pesquisa 
TABELA 6 - Indicadores de desempenho da atividade leiteira

\begin{tabular}{|c|c|c|c|c|c|c|c|c|}
\hline Propriedade & $\begin{array}{c}\text { Litros de } \\
\text { leite anual }\end{array}$ & $\begin{array}{c}\text { Receita } \\
\text { por litro } \\
\text { (R\$) }\end{array}$ & $\begin{array}{l}\text { Receita por } \\
\text { matriz (R\$) }\end{array}$ & $\begin{array}{c}\text { Receita por } \\
\text { hectare }(\mathrm{R} \$)\end{array}$ & $\begin{array}{l}\text { Lucro por } \\
\text { litro (R\$) }\end{array}$ & $\begin{array}{c}\text { Lucro por } \\
\text { matriz } \\
(\mathrm{R} \$)\end{array}$ & $\begin{array}{l}\text { Lucro por } \\
\text { hectare } \\
\text { (R\$) }\end{array}$ & $\begin{array}{l}\text { Remuneração } \\
\text { da mão de obra } \\
\text { (R\$) }\end{array}$ \\
\hline 1 & 136.875 & 1,07 & 435,21 & 398,94 & 0,52 & 137,01 & 125,59 & 502,36 \\
\hline 2 & 98.550 & 1,03 & 285,24 & 263,30 & 0,39 & 104,96 & 96,89 & 314,89 \\
\hline 3 & 98.550 & 1,00 & 276,00 & 261,47 & 0,32 & 87,74 & 83,12 & 394,83 \\
\hline 4 & 109.500 & 1,05 & 320,52 & 367,26 & 0,35 & 105,52 & 120,90 & 580,34 \\
\hline 5 & 120.450 & 1,07 & 362,16 & 390,82 & 0,53 & 173,45 & 187,17 & 650,42 \\
\hline 6 & 109.500 & 1,09 & 334,27 & 289,70 & 0,57 & 169,52 & 146,92 & $1.101,90$ \\
\hline 7 & 153.300 & 1,11 & 478,05 & 309,33 & 0,79 & 330,96 & 214,15 & $1.820,29$ \\
\hline 8 & 197.100 & 1,20 & 664,26 & 752,83 & 0,72 & 390,35 & 442,39 & $6.635,92$ \\
\hline 9 & 120.450 & 1,02 & 343,02 & 171,51 & 0,25 & 82,50 & 41,25 & 453,76 \\
\hline 10 & 109.500 & 1,07 & 294,51 & 152,71 & 0,58 & 175,06 & 90,77 & $1.225,40$ \\
\hline 11 & 164.250 & 1,17 & 538,35 & 439,47 & 0,66 & 295,35 & 241,10 & $1.969,00$ \\
\hline 12 & 186.150 & 1,16 & 606,73 & 450,71 & 0,76 & 386,88 & 287,40 & $5.029,49$ \\
\hline 13 & 197.100 & 1,12 & 618,36 & 423,09 & 0,78 & 422,98 & 289,40 & $2.749,34$ \\
\hline 14 & 197.100 & 1,25 & 689,94 & 459,96 & 0,87 & 471,08 & 314,05 & $3.454,56$ \\
\hline 15 & 186.150 & 1,21 & 629,06 & 569,28 & 0,69 & 354,04 & 320,40 & $2.360,27$ \\
\hline 16 & 136.875 & 1,11 & 426,83 & 320,13 & 0,71 & 264,65 & 198,49 & $2.381,83$ \\
\hline 17 & 120.450 & 1,12 & 379,06 & 524,85 & 0,77 & 253,08 & 350,42 & $1.518,47$ \\
\hline 18 & 120.450 & 1,02 & 345,18 & 788,98 & 0,61 & 200,56 & 458,41 & $1.069,63$ \\
\hline 19 & 142.350 & 1,21 & 482,39 & 425,64 & 0,73 & 284,81 & 251,30 & $2.136,07$ \\
\hline 20 & 240.900 & 1,28 & 863,79 & 619,76 & 0,87 & 573,81 & 411,71 & $3.060,34$ \\
\hline 21 & 105.120 & 0,95 & 278,85 & 53,11 & 0,37 & 107,51 & 20,48 & 430,06 \\
\hline 22 & 153.300 & 1,09 & 466,62 & 270,94 & 0,75 & 313,55 & 182,06 & $5.643,83$ \\
\hline 23 & 120.450 & 1,05 & 354,24 & 511,68 & 0,57 & 189,62 & 273,90 & $1.232,54$ \\
\hline 24 & 131.400 & 1,15 & 421,96 & 298,89 & 0,81 & 292,41 & 207,12 & $1.242,75$ \\
\hline 25 & 164.250 & 1,20 & 552,75 & 513,27 & 0,82 & 368,90 & 342,55 & $4.795,75$ \\
\hline 26 & 262.800 & 1,36 & $1.003,76$ & 963,61 & 0,88 & 630,52 & 605,30 & $7.566,20$ \\
\hline 27 & 131.400 & 1,13 & 415,88 & 237,65 & 0,62 & 223,34 & 127,62 & $1.786,71$ \\
\hline 28 & 240.900 & 1,30 & 875,45 & 700,36 & 0,93 & 614,74 & 491,79 & $8.606,35$ \\
\hline 29 & 97.455 & 1,03 & 280,72 & 160,41 & 0,59 & 158,55 & 90,60 & 951,33 \\
\hline 30 & 107.310 & 1,09 & 328,59 & 176,03 & 0,71 & 208,15 & 111,51 & $1.040,75$ \\
\hline
\end{tabular}

Fonte: Dados da pesquisa

Com base na Tabela 6, observa-se osindicadores de desempenho da atividade leiteira. Nota-se que, das 30 propriedades pesquisadas,no que se refere à quantidade de litros de leite anual, a propriedade rural que apresentou maior produção foi à propriedade 26 , com 262.800 mil litros de leite ao ano, e a de menor produção foi à propriedade 29, que apresentou uma produção de 97.455 mil litros ao ano.
Referente às receitas por litro, por matriz e por hectare, verifica-se que a propriedade rural que apresentou maior receita foi à propriedade 26 , e a menor receita apresentada foi à propriedade 21. A propriedade rural 26 obteve umareceita média de $\mathrm{R} \$ 1,36$ por litro de leite, no valor de $\mathrm{R} \$ 1.003,76$ por matriz e uma receita média de $\mathrm{R} \$$ 963,61 por hectare. Já a propriedade rural 21, apresentou uma receita média de $\mathrm{R} \$ 0,95$ por litro de leite, com receita 
média de $\mathrm{R} \$ 278,85$ por matriz e uma receita de $\mathrm{R} \$ 53,11$ por hectare.

Se tratando do lucro por litro, por matriz e por hectare, identifica-se que a propriedade que apresentou maior lucro por litro foi a propriedade 28 , com $\mathrm{R} \$ 0,88$ por litro e a que apresentou menor valor, foi à propriedade 9, com R $\$ 0,25$ de lucro por litro. Observa-se que, a propriedade 26 obteve maior lucro por matriz, com um valor de R\$ 630,52 e o menor lucro por matriz foi da propriedade 9, com R \$ 82,50 por matriz. Percebe-se que, relativo ao lucro por hectare, a propriedade 26 continua em destaque, com um lucro de $\mathrm{R} \$ 605,30$ por hectare, e o menor lucro por hectare foi da propriedade rural 21 , com $\mathrm{R} \$ 20,48$ por hectare.

Por fim, observa-se que referente à remuneração da mão de obra por proprietário de cada estabelecimento rural, ou seja, o lucro dividido pela quantidade de pessoas envolvidas na atividade leiteira destaca-se a propriedade 28, em que possui duas pessoas envolvidas no desenvolvimento da atividade,com uma renda média de $\mathrm{R} \$ 8.606,35$ por pessoa. E a menor remuneração da mão de obra, ficou com a propriedade $2 \mathrm{em}$ que possui quatro pessoas envolvidas na atividade leiteira, com uma renda média de $\mathrm{R} \$ 314,89$ por pessoa.

A Tabela 7 demonstra a média, o valor mínimo e máximo dos indicadores de desempenho da atividade leiteira, entre as 30 propriedades rurais da amostra analisada.

$\mathrm{Na}$ Tabela 7 observam-se os indicadores de desempenho da atividade leiteira realizada a partir do questionário aplicado nas propriedades rurais. Nela apresenta-se a quantidade de litros de leite por matriz ao dia, a quantidade de litros de leite anual, a receita por litro, por matriz e por hectare, o lucro por litro, por matrize por hectare e a remuneração da mão de obra, apresentando o total de todas as propriedades rurais eapontando também à média, o mínimo e o máximo das propriedades rurais.

$\mathrm{Na}$ Tabela 7, nota-se que há uma considerável diferença entre osvalores mínimos e os máximos em relação à quantidade de litros de leite por matrizes ao dia. Os resultados do estudo vão ao encontro da pesquisa de Brand et al. (2014), a qual também observou queo aumento da produtividade do leite das matrizes pode estar relacionadocom a alimentação adequada, a raça das matrizes e o manejo das mesmas.

Identifica-se também na Tabela 7,uma notável diferença entre o mínimo e o máximo em relação à receita por matriz, onde o mínimo apresenta uma receita de $\mathrm{R} \$ 1.115,39$ e omáximo ressalta uma receita de $\mathrm{R} \$$ 48.180,48; e também referente ao lucro por hectare, onde o mínimo está representado por apenas $\mathrm{R} \$ 20,48$ de lucro e o máximo de $\mathrm{R} \$ 7.124,78$. A pesquisa corrobora com o estudo de Carlotto, Filippi e Marcello (2011), onde indicam que uma pequena propriedade pode obter lucro desde que seus custos não ultrapassem as despesas,salienta-se quea atividade leiteira pode ser uma atividade rentável mesmo em sistemas menos intensivos na utilização dos recursos produtivos como: animais, terra e mão de obra.

Na Tabela 7 nota-se também uma diferença na quantidade de litros de leite anual e em suas receitas (litro, matriz e hectare), isto se explica pela quantidade de matrizes que os produtores possuem em suas propriedades, onde produtores que possuem um número maior de matrizes apresentarão maior produção de litros de leite, e assim, vice-versa. Desse modo, evidencia-se que quanto maior for à quantidade de matrizes e de litros de leite, maior será o retorno sobre o investimento, ou seja, seu lucro.

TABELA 7 - Indicadores de desempenho da atividade leiteira

\begin{tabular}{|c|c|c|c|c|}
\hline Indicadores de desempenho & Total & Média & Mínimo & Máximo \\
\hline Litros de leite matriz ao dia & 407 & 14 & 9 & 24 \\
\hline Litros de leite anual & 4.459 .935 & 148.664 & 97.455 & 262.800 \\
\hline Receita por litro & 33,71 & 1,12 & 0,95 & 1,36 \\
\hline Receita por matriz & $14.352,74$ & 925,92 & 276,00 & $14.351,74$ \\
\hline Receita por hectare & $12.265,68$ & 408,86 & 53,11 & 963,61 \\
\hline Lucro por litro & $11.527,14$ & 384,24 & 44,80 & $1.261,03$ \\
\hline Lucro por matriz & $8.371,59$ & 279,05 & 82,50 & 630,52 \\
\hline Lucro por hectare & $7.124,78$ & 459,66 & 20,48 & $7.124,78$ \\
\hline Remuneração da mão de obra & $72.705,37$ & $2.423,51$ & 314,89 & $8.606,35$ \\
\hline
\end{tabular}

Fonte: Dados da pesquisa

Organizações Rurais \& Agroindustriais, Lavras, v. 20, n. 3/4, p. 187-201, 2018 
De forma geral, os resultados encontrados colaboram as pesquisas de Zanin et al. (2013 e Gollo et al. (2015), onde a atividade leiteira apresentou-se rentável economicamente e financeiramente nas propriedades analisadas, demonstrando bons resultados aos proprietários rurais e possibilitando novos investimentos na atividade. Destaca-se também que a atividade leiteira é praticada pelos próprios integrantes das famílias e que esta atividade é a principal fonte de renda dos produtores rurais, neste aspecto os achados também colaboram com os estudos deCarlotto, Filippi e Marcello (2011) e Viana, Costa e Santos (2014) que evidenciam a importância do uso da contabilidade no meio rural como instrumento de gestão e análise dos resultados das atividades.

\section{CONCLUSÕES E PESQUISAS FUTURAS}

O estudo teve por objetivo comparar indicadores de desempenho econômico-financeiro da produção leiteira em propriedades rurais de Formosa do Sul - SC.A partir da coleta e análise dos dados relacionados à receita e aos custos da atividade leiteira identificou-se os resultadosque cada propriedade obteve. Os dados coletados referem-se ao período de novembro de 2016 a janeiro de 2017.A contabilidade é uma importante ferramenta de gestão para que entidades possam ter informações úteis e confiáveis no processo de tomada de decisão. Já os indicadores de desempenho são ferramentas essenciais para que gestores possam monitorar e avaliar o processo produtivo, embasando a análise crítica dos resultados e ter apoio no processo de tomada de decisão.

Os resultados do estudo destacam uma relação positiva entre propriedades rurais com maior número de matrizes em lactação e o lucro obtido. Nota-se que quanto maior à quantidade e qualidade do leite, melhor será a remuneração da receita pela comercialização do produto.

Observou-seque, das trinta propriedades entrevistadas, a propriedade rural que apresentou maior destaque foi à propriedade 26. No período analisado, a mesma apresentou uma média de 48 matrizes em lactação, sendo as raças de suas matrizes, Jersey e Holandesa, possuindo 50 hectares de terra direcionados para a atividade leiteira. A mesma apresentou uma média de 24 litros de leite por matriz ao dia e apresentou uma receita de $\mathrm{R} \$ 1,36$ por litro de leite, apontando uma receita total de $\mathrm{R} \$ 48.180,48$ por mês. Referente aos custos em geral, apresentou um valor total de R\$ $17.915,67$ por mês, e lucro total de $\mathrm{R} \$ 30.264,81$ por mês, no qual é subdividido pelos quatro integrantes da família que atuam na atividade leiteira. Vale destacar também que,das trinta propriedades entrevistadas, a propriedade 26 foi à única que apresentou acompanhamento da contabilidade para suas atividades.

Nota-se também que das trinta propriedades analisadas, a propriedade rural que apresentou menor desempenho econômico financeiro foi à propriedade 21 , onde comparada as demais foi a que apresentou resultados inferiores. E perceptível, quea mesma apresentou o mínimo da receita por litro, por matriz e por hectare eapontou também omínimo em lucro por litro e por hectare. No período analisado, a mesma apresentou em média4 matrizes em lactação, possuindo 21 hectares de terra ao todo, porém apenas 5 destes direcionados para a atividade leiteira. A mesma apresentou uma média de 9,6 litros de leite por matriz ao dia e receita de $\mathrm{R} \$ 0,95$ por litro de leite, apresentando uma receita total de $\mathrm{R} \$ 1.115,39$ por mês, custos de $\mathrm{R} \$ 685,33$ por mês, e lucro total de $\mathrm{R} \$$ 430,06 por mês, sendo que apenas uma pessoa da família atua nesta atividade.

Recomenda-se para novos estudos um período maior para a análise, incluindo outras atividades, para uma comparação entre as atividades e outras propriedades rurais, visando contribuir com as discussões sobre a importância da contabilidade no meio rural.Embora a limitação da amostra de 30 propriedades rurais de agricultura familiar, destacamos que o conjunto de indicadores pode ser utilizado de forma genérica por outras entidades rurais que desenvolvem a atividade leiteira.

De modo geral, os resultados demonstraram que as atividades desenvolvidas nas propriedades rurais estudadas são rentáveis economicamente e financeiramente e contribuem com a geração de caixa e renda das famílias. Os resultados do estudo identificam a importância do uso da contabilidade como instrumento de apoio à gestão das entidades rurais, visando identificar os custos e os resultados das atividades desenvolvidas possibilitando a análise dos investimentos realizados e a melhor tomada de decisão.

Destaca-se a importância da contabilidade como instrumento de controle e planejamento das atividades rurais, contribuindo com a análise e gestão dos custos e dos investimentos dos empreendimentos desenvolvidos no meio rural, como alternativa para a permanência e satisfação das famílias que exploram o meio rural como alternativa econômico-financeira, de renda e emprego. 


\section{REFERÊNCIAS}

BEWLEY, J.; PALMER, R. W.; JACKSON-SMITH, D. B. A comparison of free-stall barns used by modernized wisconsin dairies. Journal of Dairy Science, v. 84, n. 2, p. 528-541, 2001.

BONAMIGO, A.; FERENHOF, H. A.; FORCELLINI, F. A. Dairy ecosystem barriers exposed-a case study in a family production unit at western Santa Catarina, Brazil. Organizações Rurais \& Agroindustriais, v. 19, n. 1, p.1-7, 2017.

BRAND, S. I.; MUMBACH, G. L.; DIEL, M. I.; PORTELA, V. O.; SCHNEIDER, F. J.; SILVA, D. R. Dados preliminares sobre características de propriedades de bovinocultura leiteira da região Nordeste do RS. Revista Interdisciplinar de Ensino, Pesquisa e Extensão, v. 2, n. 1, p. 1-12, 2014.

CANDIDO, E. P.; FILHO, E. C. P.; NETO, S. G.; SANTOS, E. M.; DE MOURA, J. F. P. Análise dos sistemas de produção de bovinos leiteiros do Cariri Oriental da Paraíba. Revista Científica de Produção Animal, v. 17, n. 1, p. 7-17, 2015.

CARLOTTO, I.; FILIPPI, A. J.; MARCELLO, E. I. Estudo de viabilidade da produção de leite em uma propriedade familiar rural do município de Francisco Beltrão- PR. Revista Ciências Empresariais da UNIPAR, v. 12, n.1, p.95- 109, 2011.

COSTA, V. de S.; ASSUNÇÃO, A. B. A.; DA COSTA, M. M. B.; CHACON, M. J. M. Análise de custos a partir da cadeia do valor do leite e seus derivados na região Seridó do Rio Grande do Norte. Revista Ambiente Contábil, v. 7, n. 1, p. 89-108, 2015.

CREPALDI, S. A. Contabilidade rural: uma abordagem decisorial. 6. ed. São Paulo: Atlas, 2011.

DAL MAGRO, C. B.; DI DOMENICO, D.; KLANN, R. C.; ZANIN, A. Contabilidade rural: comparativo na rentabilidade das atividades leiteira e avícola. Custos e (a)gronegocioonline, v. 9, n. 1, p. 2-22, 2013.

DETTMER, C. A.; SILVA, N. L. S. Agricultura Familiar estudo de caso no assentamento Teijin, município de Nova Andradina, MS. Revista Nera,n. 29, p. 133-150, 2015.
DUARTE, J. S.; FERRI, A.; HONORATO, C. A. Aspectos da viabilidade econômica na pecuária leiteira. Revista Comunicação \& Mercado, v. 3, n. 7, p. 4-15, 2014.

EMPRESA BRASILEIRA DE PESQUISA AGROPECUÁRIA - EMBRAPA. Anuário leite 2019. Disponível em: file:///C:/Users/Silvana.Uno/Downloads/ Anuario-LEITE-2019.pdf. Acesso em: 23 jan. 2020.

FACHIN, O. Fundamentos de Metodologia. 4. Ed. São Paulo: Saraiva, 2005. 200 p.

GIL, A. C. Como elaborar projetos de pesquisa. 5. ed. São Paulo: Atlas, 2010. 184 p.

GHISELLINI, P.; PROTANO, G.; VIGLIA, S.; GAWORSKI, M.; SETTI, M.; ULGIATI, S. Integrated agricultural and dairy production within a circular economy framework. A comparison of Italian and Polish farming systems. Journal of Environmental Accounting and Management, v. 2. n. 4, p.367-384, 2014.

GOLLO, V.; KRUGER, S. D.; MAZZIONI, S. DA CUNHA, P. R. Análise comparativa do resultado econômico e financeiro entre as atividades suinícola e leiteira. Custos e @gronegócio online, v. 11, n. 2, p. 93-113, 2015.

GONÇALVES, A. C. S.; JÚNIOR, L. C. R.; FONSECA, M. I.; NADRUZ, B. V.; BÜRGER, K. P.; ROSSI, G.A. M. Assistência técnica e extensão rural: sua importância para a melhoria da produção leiteira. Relato de caso. Revista Brasileira de Higiene e Sanidade Animal, v. 8, n. 3, p. 47-61, 2014.

GONZAGA, R. P.; CRUZ, A. P. C.; PEREIRA, C. A.; LUZ, A. T. M. Associação entre missão institucional declarada por empresas brasileiras e seus indicadores de desempenho. Revista Contabilidade Vista \& Revista, v. 26, n. 1, p. 15-34, 2015.

KRUGER, S. D.; CECCATTO, L.; MAZZIONI, S.; DI DOMENICO, D.; PETRI, S. M. Análise comparativa da viabilidade econômica e financeira das atividades avícola e leiteira. Revista Ambiente Contábil, v. 9, n. 1, p. 37-55, 2017.

KRUGER, S. D.; GLUSTAK, E.; MAZZIONI, S.; ZANIN, A.A contabilidade como instrumento de gestão dos estabelecimentos rurais. REUNIR: Revista de Administração, Contabilidade e Sustentabilidade, v. 4, n. 2, p. 134-153, 2014. 
KRUGER, S. D.; DA SILVA, M. A. L.; DE VARGAS MORES, G.; PETRI, S. M. Fatores determinantes para a sucessão familiar em estabelecimentos rurais da região oeste de Santa Catarina. Extensão Rural, v. 25, n. 4, p. 57-70, 2018.

LOPES, M. A.; SANTOS, G.; CARVALHO, F. M. Comparativo de indicadores econômicos da atividade leiteira de sistemas intensivos de produção de leite no estado de Minas Gerais. Revista Ceres, v. 59, n. 4, p. 458-465, 2012.

MARION, J. C. Contabilidade Rural. Contabilidade Agrícola. Contabilidade da Pecuária. Imposto de Renda - Pessoa Jurídica. 13. ed. São Paulo: Atlas, 2012.

MAZZIONI, S.; DEDONATTO, O.; GALANTE, C. Aspectos introdutórios do estudo da contabilidade. Chapecó: Argos, 2012.

OLIVEIRA, N. C. Contabilidade do agronegócio: teoria e prática. 2. ed. Curitiba: Juruá, 2010.

PALHARES, J. C. P.; PEZZOPANE, J. R. M. Water footprint accounting and scarcity indicators of conventional and organic dairy production systems. Journal of Cleaner Production, v. 93, p. 299-307, 2015.

PIOVESANI, V.; BORTOLUZZI, S. C.; SILVA, M. R. Avaliação de desempenho em uma propriedade rural de pequeno porte do extremo oeste de Santa Catarina. REUNA, v. 20, n. 3, p. 109-128, 2015.

RAUPP, F. M; BEUREN, I. M.Metodologia da pesquisa aplicável as ciências sociais. In: BEUREN, Ilse Maria (Org.). Como elaborar trabalhos monográficos em contabilidade: teoria e prática. 3. ed. São Paulo: Atlas, 2012. p. 76-195.

SABBAG, O. J.; COSTA, S. M. A. L. Análise de custos da produção de leite: aplicação do método de Monte Carlo. Extensão Rural, v. 22, n. 1, p. 125-145, 2015.
SENA, A. L. dos S.; SANTOS, M. A. S.; DOS SANTOS, J. C.; HOMMA, A. K. O. Avaliação do nível tecnológico dos produtores de leite na região Oeste do Pará. Revista de Economia e Agronegócio - REA, v. 10, n. 3, p. 397418, 2013.

SOUZA, M. P.; FILHO, T. A. S.; MULLER, C. A. S.; SOUZA, D. B. Custos da produção em unidades rurais produtoras de leite: avaliação do gerenciamento e produtividade. Custos e @gronegócioonline, v. 7, n.1, p. 140-158, 2011.

SPERS, R. G.; WRIGHT, J. T. C.; AMEDOMAR, A. A. Scenarios for the milk production chain in Brazil in 2020. Revista de Administração, v. 48, n. 2, p. 254-267, 2013.

TICHENOR, N. E.; PETERS, C. J.; NORRIS, G. A.; THOMA, G.; GRIFFIN, T. S. Life cycle environmental consequences of grass-fed and dairy beef production systems in the Northeastern United States. Journal of Cleaner Production, v. 142, n.4, p. 1619-1628, 2017.

VIANA, C. M. S.; COSTA, J. M. E.; SANTOS, J. K. B. A importância da contabilidade rural na pecuária. Revista Saber Eletrônico on-line, s.v, n. 2, p. 5-23, 2014.

ZANIN, A.; OENNIN, V.; TRES, N.; KRUGER, S. D.; GUBIANI, C. A. Gestão das propriedades rurais do Oeste de Santa Catarina: as fragilidades da estrutura organizacional e a necessidade do uso de controles contábeis. Revista Catarinense de Ciência Contábil CRC SC, v. 13, n. 40, p. 9-19, 2013.

ZANIN, A; BAGATINI, F. M. The economic and financial feasibility of a biodigester: A sound alternative for reducing the environmental impact of swine production. In: CURKOVIC, S. (Org). Susteinable Development - Authoritative and leading edge content for environmental management. Rijeka, Croatia: Intech. p. 371-388, 2012. 